\title{
Assess Calibration Consistency of MODIS and AVHRR Thermal Infrared Bands Using SNO Observations Corrected for Atmospheric Effects
}

\author{
Aisheng Wu, Yong Xie, Xiaoxiong Xiong, and I-Wen Chu
}

\begin{abstract}
Monitoring environmental changes from space requires extremely well-calibrated observations to achieve the necessary high accuracy and stability. The calibration differences between the Moderate Resolution Imaging Spectroradiometer (MODIS) and the Advanced Very High Resolution Radiometer (AVHRR) thermal bands provide a valuable quality assessment of the instrument performance. This letter compares the calibration differences between the Aqua MODIS and NOAA-18 AVHRR bands at 11.0 and $12.0 \mu \mathrm{m}$ using simultaneous nadir overpass observations obtained in nearly parallel orbits. Impacts due to the relative spectral-response differences between the two sensors are estimated by MODTRAN simulations with real-time atmospheric profiles of temperature, water vapor, atmospheric pressure and ozone, and surface skin temperatures. Results show that the temperature difference after the removal of atmospheric impacts is within $0.30 \mathrm{~K}$ (or $0.40 \%$ in radiance) across the effective calibration range for the 11.0- $\mu \mathrm{m}$ band/channel. For the $12.0-\mu \mathrm{m}$ band, the differences are $0.40 \mathrm{~K}$ (or $0.50 \%$ ) at the typical radiance and up to $0.70 \mathrm{~K}$ (or $0.90 \%$ ) close to the maximum radiance, indicating an excellent calibration consistency between MODIS and AVHRR for both bands.
\end{abstract}

Index Terms-Advanced Very High Resolution Radiometer (AVHRR), calibration, MODerate Resolution Imaging Spectroradiometer (MODIS), MODerate resolution atmospheric TRANsmission (MODTRAN), simultaneous nadir overpass (SNO), temperature.

\section{INTRODUCTION}

$\mathbf{T}$ HE Moderate Resolution Imaging Spectroradiometer (MODIS) is a key instrument of the National Aeronautics and Space Administration's Earth Observing System (EOS) mission currently operating on both Terra and Aqua satellite platforms (launched in December 1999 and May 2002, respectively) in a near Sun-synchronous polar orbit [1]-[3]. MODIS is designed from a number of heritage sensors, including the Advanced Very High Resolution Radiometer (AVHRR), which has been in operation for nearly three decades on board the National Oceanic and Atmospheric Administration (NOAA)

Manuscript received May 2, 2011; revised September 9, 2011; accepted October 12, 2011. Date of publication November 29, 2011; date of current version March 7, 2012.

A. Wu, Y. Xie, and I.-W. Chu are with Sigma Space Corporation, Lanham, MD 207C6 USA (e-mail: aisheng.wu@sigmaspace.com; yong.xie@ sigmaspace.com: mike.chu@ sigmaspace.com).

$\mathrm{X}$. Xiong is with the Sciences and Exploration Directorate, NASA Goddard Space Flight Center, Greenbelt, MD 20771 USA (e-mail: xiaoxiong-1@ nasa.gov).

Digital Object Ićentifier 10.1109/LGRS.2011.2172677 polar-orbiting satellites [4]. MODIS and AVHRR are the two most important sensors that make global observations to derive various products which monitor land, ocean, and atmospheric processes. Monitoring these environmental changes from space requires extremely well-calibrated observations to achieve the required high accuracy and stability [5].

The MODIS instrument has 36 spectral bands covering a wavelength range from 0.4 to $14.4 \mu \mathrm{m}$ with Earth scene observations sampled at three nadir resolutions of $0.25,0.50$, and $1.0 \mathrm{~km}$. The 16 thermal emissive bands (TEBs, i.e., band 20-25 and 27-36) are calibrated on-orbit using a large aperture V-grooved blackbody (BB) controlled at a constant temperature of $290 \mathrm{~K}$ for Terra and $285 \mathrm{~K}$ for Aqua. The three AVHRR thermal infrared channels $(3.7,11.0$, and $12.0 \mu \mathrm{m}$ of channels $3 \mathrm{~b}, 4$, and 5, respectively) are calibrated in-flight with a fullaperture honeycomb BB as an internal calibration target (ICT). However, the ICT temperature varies with instrument ambient environment, with temperature floating at around $290 \mathrm{~K}$ [6], [7]. The absolute radiometric calibration of the MODIS TEB and AVHRR infrared channels is related to the standards of the National Institute of Standards and Technology.

Although the calibration of MODIS and AVHRR sensors each relies on measurements of the on-board BB and the cold-space background, the calibration methodology operates differently, depending on the design of the instrument. The independent calibration of thermal bands between MODIS and AVHRR provides a valuable quality assessment of the performance of each instrument. A direct comparison of temperature obtained from near-simultaneous nadir overpasses (SNOs) shows that the differences are generally within $0.25 \mathrm{~K}$ at typical scene temperatures for the atmospheric window bands [8]-[10]. A clear dependence of the temperature difference on scene temperature has been found between MODIS and AVHRR and for most pairs of NOAA series AVHRR [11]. Since the MODIS spectral-band passes are significantly narrower than those of the AVHRR channels, temperature differences between the two sensors could be scene temperature dependent and atmospheric water vapor sensitive. However, the results of previous MODIS and AVHRR comparison did not account for the impacts of atmospheric water vapor content. To better quantify the sensor differences caused by calibration, it is necessary to remove atmospheric associated impacts on the calculation of the temperature differences. In the past, the lack of realtime observations of atmospheric temperature and humidity profiles that coincided in time with satellite observations made 

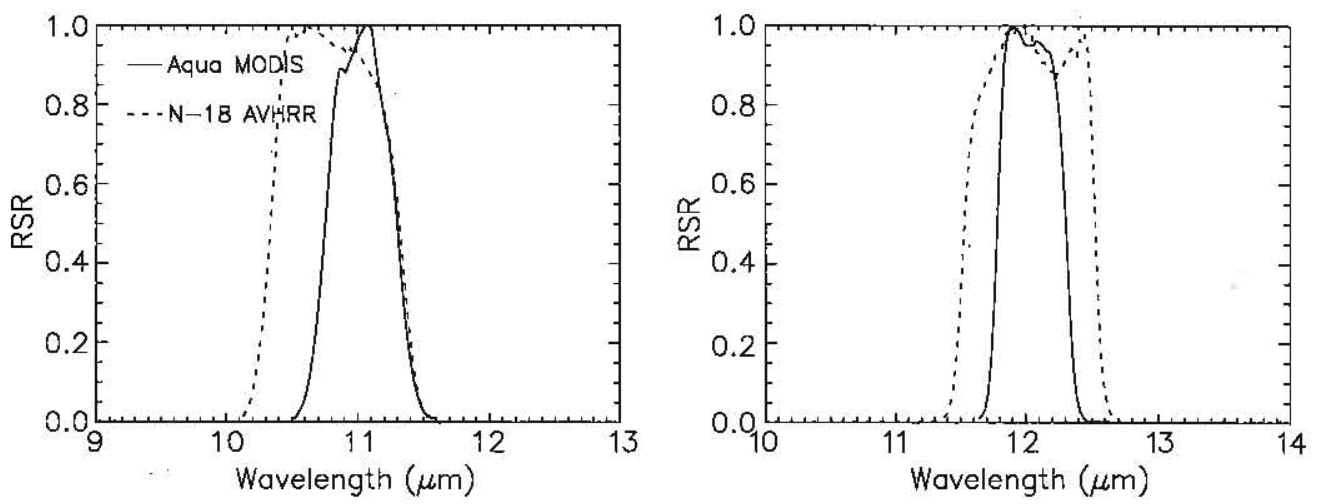

Fig. 1. RSR of the two spectrally matched bands/channels (11.0 and 12.0 $\mu \mathrm{m}$ ) of Aqua MODIS (31 and 32) and NOAA-18 AVHRR (channels 4 and 5).

it difficult to evaluate such impacts since the atmospheric temperature and water vapor profiles change constantly with time and geolocation. Recent developments and improvements in the sounding product have allowed sensor-retrieved realtime surface temperatures and atmospheric profiles to become available.

This letter uses observed temperature differences obtained from Aqua MODIS and NOAA-18 AVHRR SNO observations to examine their calibration differences for thermal bands at 11.0 and $12 \mu \mathrm{m}$. Impacts of atmospheric water vapor on the calculation of the temperature differences are simulated by MODerate resolution atmospheric TRANsmission (MODTRAN4), Revision 1 [12], with real-time atmospheric profiles obtained from the Atmospheric Infrared Sounder (AIRS) on the Aqua spacecraft. Currently, the latest version (MODTRAN5) is available (http://www.ontar.com/ Software/ProductDetails.aspx ?item $=$ modtran), and significant improvements are made for calculations of solar spectral radiances. Thus, it still justifies our use of MODTRAN4 in this letter for the atmospheric window spectral region. We selected Aqua MODIS and NOAA-18 AVHRR because their SNO events occur periodically in overlapping orbits with crossover angles at nearly $0^{\circ}$, thus providing extra opportunities to examine and compare calibration stability of the two sensors. To ensure the quality of the comparison, only data collected over relatively homogeneous surfaces are used. Orbits over different latitude sections are selected to cover a wide range of scene temperature. The objectives of this letter are to: 1) provide MODTRAN simulations of MODIS and AVHRR realtime temperature differences caused by their relative spectral response (RSR) differences and 2) provide quantitative assessments of MODIS and AVHRR calibration differences by combination of SNO observations with the real-time simulation of atmospheric influences.

\section{Methodology}

The comparison between Aqua MODIS and NOAA-18 AVHRR is conducted for two spectrally matched bands (Fig. 1), which are MODIS band $31(11.03 \mu \mathrm{m})$ to AVHRR channel $4(10.79 \mu \mathrm{m})$ and MODIS band $32(12.02 \mu \mathrm{m})$ to AVHRR channel $5(11.92 \mu \mathrm{m})$. The effective temperature $(T)$, at which the underlying surface radiates as a $\mathrm{BB}$, is used to evaluate the differences between the two sensors. To accurately compute $T$, the measured brightness temperature $\left(T_{E}\right)$ is calculated based on the central wavelength $\left(\lambda_{c}\right)$ of a given band

$$
T_{E}=\frac{c_{2} / \lambda_{c}}{\ln \left[1+c_{1} /\left(L \lambda_{c}^{5}\right)\right]}
$$

where $c_{1}$ and $c_{2}$ are the Planck equation constants and $L$ is the radiance of a band. To determine $T$, a linear regression between $T$ and $T_{E}$ is used

$$
T=\left(T_{E}-A\right) / B
$$

Coefficients $A$ and $B$ for NOAA series AVHRR are provided in the NOAA KLM User's Guide (https://www.ncdc. noaa.gov/oa/pod-guide/ncdc/docs/intro.htm), while coefficients for Terra and Aqua MODIS are derived using the same procedure [8], [9], [13]. Basically, coefficients $A$ and $B$ are determined from the linear regression between $T_{E}$ and $T$, with $T$ changing from $180 \mathrm{~K}$ to $320 \mathrm{~K}$ at an interval of $0.1 \mathrm{~K}$. The theoretical value of $T_{E}$ is computed by convolving the RSR with the BB spectral radiance at $T$. The relative difference in $T$ between MODIS and AVHRR is calculated by

$$
\Delta T=T_{\text {MODIS }}-T_{\text {AVHRR }}
$$

where $T_{\text {MODIS }}$ and $T_{\mathrm{AVHRR}}$ are the effective temperatures for MODIS and AVHRR, respectively.

Theoretical values of $\Delta T$ due to the MODIS and AVHRR RSR differences are estimated from MODTRAN simulations. Our simulation uses AIRS-observed real-time temperature, pressure, humidity and ozone profiles, and skin temperatures obtained during the MODIS and AVHRR SNO periods. Thus, the atmospheric profile data are measured at the same time as the Aqua radiance measurements, while time lags in SNO data between MODIS and AVHRR are restricted to be within $30 \mathrm{~s}$. Each simulation provides a real-time top-of-atmosphere (TOA) radiance spectrum $[L(\lambda)]$. Given the RSR for MODIS and AVHRR, a simulated band spectral radiance $\left(L^{\text {simu }}\right)$ is determined using

$$
L^{\mathrm{simu}}=\frac{\int_{\lambda 1}^{\lambda 2} R S R(\lambda) L(\lambda)}{\int_{\lambda 1}^{\lambda 2} R S R(\lambda) .}
$$

By replacing $L$ in (1) with $L^{\text {simu }}$ and following the same calculation path from (1)-(3), the simulated relative difference 


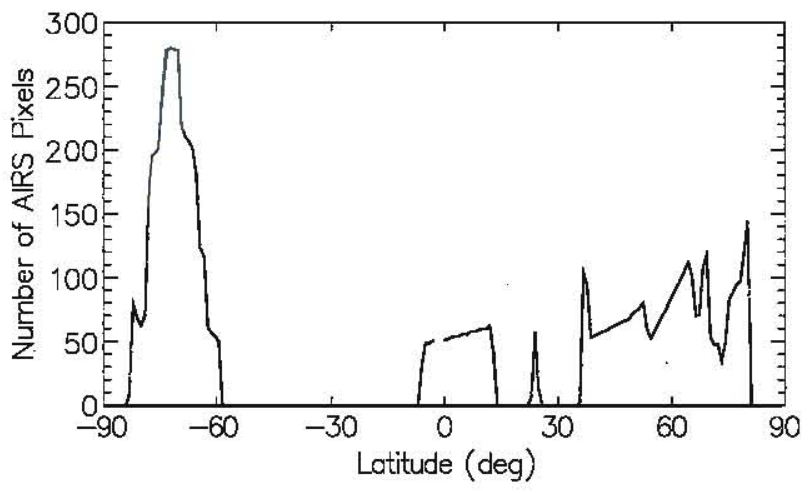

Fig. 2. Histogram of sampled 50-km areas along latitude.

in $T$ between MODIS and AVHRR can be determined. The remaining differences between the sensors observed and simulated (i.e., theoretical values) $\Delta T$ are considered to be caused by relative calibration differences, i.e.,

$$
\Delta T^{\mathrm{calib}}=\Delta T^{\mathrm{obs}}-\Delta T^{\mathrm{simu}}
$$

\section{RESULTS}

\section{A. Observed and Simulated $\Delta T$}

The observational data are collected from 13 Aqua MODIS and NOAA-18 AVHRR SNO events that occurred between 2006 and 2010 in nearly overlapping orbits, meaning that the crossover angles between the two sensors are close to $0^{\circ}$. The time difference between the two instruments viewing the same Earth scene is within $30 \mathrm{~s}$ [14]. These orbits are selected over different latitude regions and seasons so that the collected data sets cover a wide range of scene temperatures. Sampled MODIS L1B 1-km and AVHRR L1B 4-km global area coverage pixels within a $50-\mathrm{km}$ area at nadir are averaged to match the horizontal resolution of the AIRS-retrieved atmospheric profiles (Fig. 2). To reduce the impact of spatial inhomogeneity on the average, sampled pixels within each $50-\mathrm{km}$ area are examined for the standard error of $T$. Averaged points with standard errors larger than $2.0 \mathrm{~K}$ are excluded from our results.

Because AVHRR channels have a relatively wider distribution of RSR than those of the spectrally matched MODIS bands (Fig. 1), it is expected that scene temperature and atmospheric water vapor can have an impact on the differences between $T_{\text {MODIS }}$ and $T_{\mathrm{AVHR}}$. Fig. 3 shows $\Delta T^{\text {obs }}$ versus $T$ for the 11.0- and $12.0-\mu \mathrm{m}$ bands. As expected, in general, $\Delta T$ is dependent on $T$. The $12.0-\mu \mathrm{m}$ band shows stronger dependence on $T$ at high temperatures. Recent studies used the split-window technique (i.e., the differences of $T$ between 11.0and $12,0-\mu \mathrm{m}$ bands) to determine the total atmospheric water vapor content [15]. Thus, it is important to remove the impact of existing atmospheric water vapor on the calculation of $\Delta T$ in order to detect small calibration differences between sensors.

Since the atmospheric temperature and water vapor profiles change constantly with time and geolocation, it becomes necessary to use simulation with real-time atmospheric profiles so that their effects on the calculation of $\Delta T$ can be captured. In this letter, the atmospheric profiles of retrieved temperature, water vapor, atmospheric pressure and ozone, and surface skin

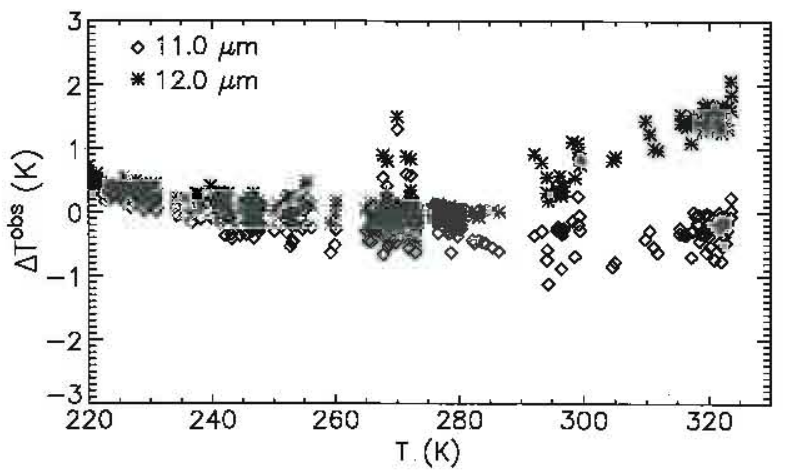

Fig. 3. $\Delta T^{\text {obs }}$ versus $T$ for the two spectrally matched bands/channels of Aqua MODIS and NOAA-18 AVHRR at 11.0 and $12.0 \mu \mathrm{m}$. Each point is an averaged value over the AIRS pixel footprint at a nadir resolution of $50 \mathrm{~km}$. Data are collected from Aqua MODIS and NOAA-18 observations collected from 13 SNO events in nearly overlapping orbits between 2006 and 2010 .

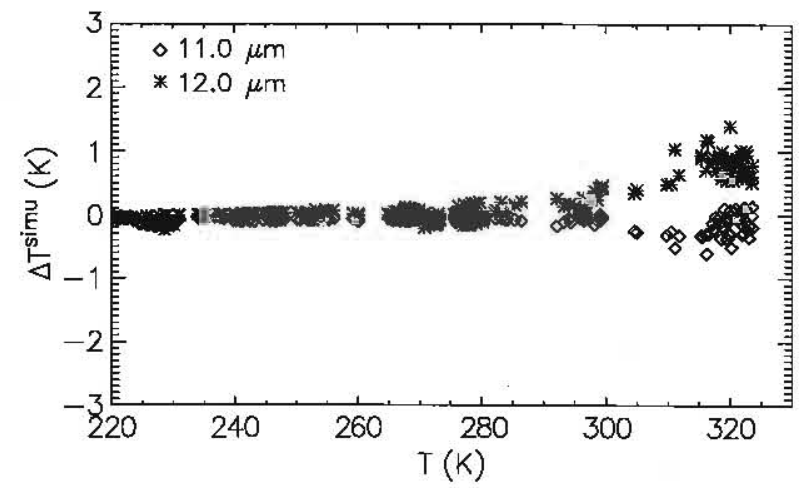

Fig. 4. $\Delta T^{\text {simu }}$ versus $T$ for the two spectrally matched bands/channels of Aqua MODIS and NOAA-18 AVHRR obtained from MODTRAN simulations with measured real-time atmospheric temperature, water vapor, pressure and ozone profiles, and skin temperatures from AIRS standard product. All data points come from simulations with atmospheric profiles matching in time and location with the SNO points shown in Fig. 3.

temperature are taken from the AIRS standard retrieval product [16], collected at the same time over the MODIS and AVHRR SNO regions. The profile horizontal resolution is $50 \mathrm{~km}$, which matches with the area in size used to average over for sampled pixels, and the vertical resolution is 28 levels between 1000 and $0.1 \mathrm{mb}$. Given each AIRS-retrieved real-time atmospheric profile, a simulation of TOA radiance spectrum $[L(\lambda)]$ at a spectral interval of $0.001 \mu \mathrm{m}(1.0 \mathrm{~nm})$ is produced using MODTRAN4 [12]. The simulated spectral radiance $L^{\text {simu }}$ of the MODIS and AVHRR bands is determined based on (4). Then, the simulated $T_{\mathrm{MODIS}}$ and $T_{\mathrm{AVHRR}}$ are computed using (1) and (2). Fig. 4 shows $\Delta T^{\text {simu }}$ versus $T$ for the two MODIS and AVHRR bands at 11.0 and $12.0 \mu \mathrm{m}$. Results show that there is almost no temperature dependence for $\Delta T^{\text {simu }}$ when $T$ is lower than $300 \mathrm{~K}$. This is likely due to the fact that most SNO events for low-temperature scenes occur at around $70^{\circ} \mathrm{N} / \mathrm{S}$ latitude, where the atmospheric water content is significantly low. Results also indicate that at high temperatures, $\Delta T^{\text {simu }}$ shows a stronger dependence on $T$ in the $12.0-\mu \mathrm{m}$ band than that in the $11.0-\mu \mathrm{m}$ band. Comparison between observed and simulated $\Delta T$ provided in Figs. 3 and 4 reveals that the observed $\Delta T$ has a stronger dependence on $T$. 

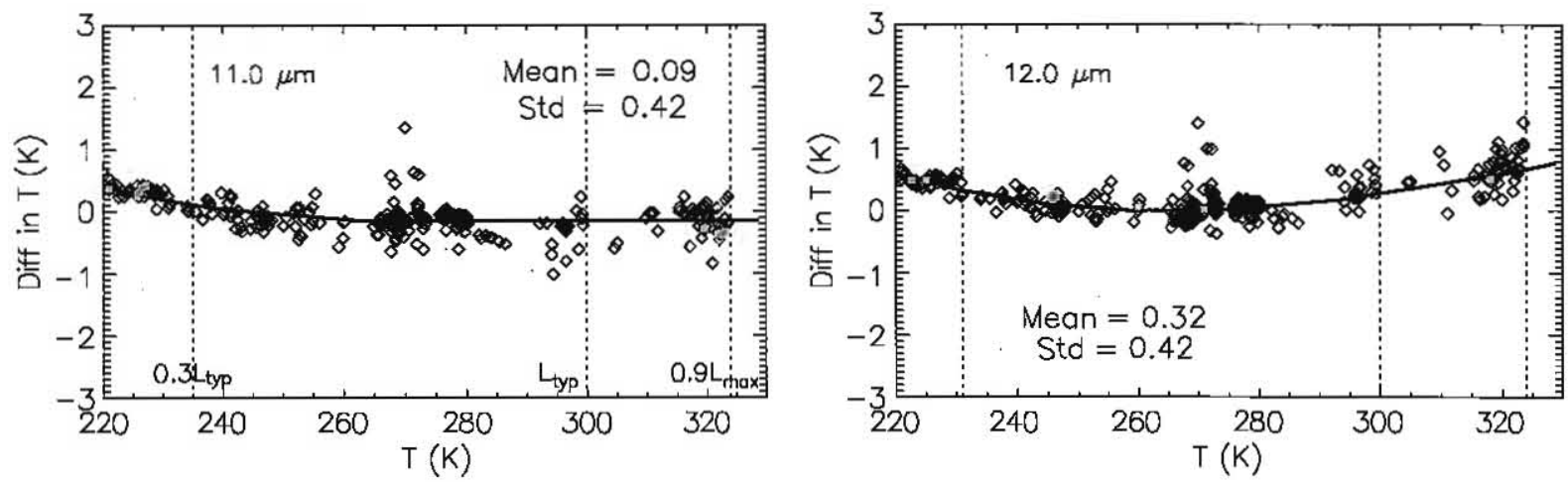

Fig. 5. Remaining temperature differences versus $T$ obtained by subtracting the simulated $\Delta T$ from the observed $\Delta T$. Three vertical lines represent temperatures at 0.3 of the typical radiance, the typical radiance, and 0.9 of the maximum radiance for MODIS bands.

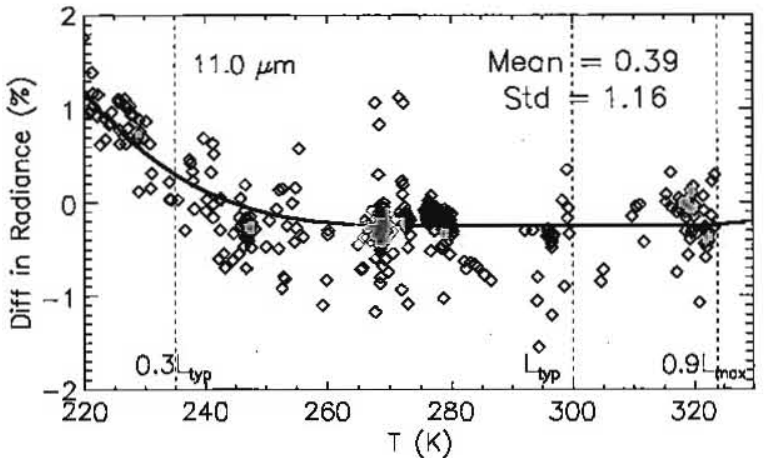

Fig. 6. Remaining differences in radiance (in percentage) versus $T$.

\section{B. Calibration Differences}

When a subtraction between the observed and simulated $\Delta T$ pairs of points is conducted, i.e., between Figs. 3 and 4, the remaining differences are considered to be caused by a relative calibration bias between MODIS and AVHRR according to (5). Fig. 5 shows the remaining differences versus $T$ for the 11.0and $12.0-\mu \mathrm{m}$ bands. To better understand the reason for the remaining differences related to calibration, the differences are examined at three temperatures corresponding to three radiance levels used in MODIS prelaunch calibration: 0.3 of the typical radiance, typical radiance, and 0.9 of the maximum radiance, respectively. Lines corresponding to these three temperatures are marked in Fig. 5. Values of the typical radiance are provided based on the science product [1]. MODIS calibration requirements are $0.5 \%$ at the typical radiance for the 11.0 - and $12.0-\mu \mathrm{m}$ bands. At the 0.3 typical radiance and 0.9 maximum radiance, an extra $1.0 \%$ is added to the calibration requirements [17], indicating that the calibration quality is ensured for temperatures between $T$ at $0.3 L_{\text {typ }}$ and $T$ at $0.9 L_{\max }$. For AVHRR, there is a similar stringent requirement at typical radiance, mainly focusing on the accuracy of sea surface temperature retrieval (http://www2.ncdc.noaa.gov/docs/klm/html/c7/sec71.htm). Results show that there is an excellent agreement between Aqua MODIS and NOAA-18 AVHRR for the 11.0- $\mu \mathrm{m}$ band for $T$ from temperatures at $0.3 L_{\text {typ }}$ to $0.9 L_{\max }$, with a mean difference of less than $0.09 \mathrm{~K}$. For the $12.0-\mu \mathrm{m}$ band, the mean difference at $L_{\text {typ }}$ is $0.32 \mathrm{~K}$, and there is a slight temperature-dependent trend with a warm bias (up to $0.60 \mathrm{~K}$ ) for temperatures both close to $T$ at $0.3 L_{\mathrm{typ}}$ and $0.9 L_{\max }$. Fig. 6

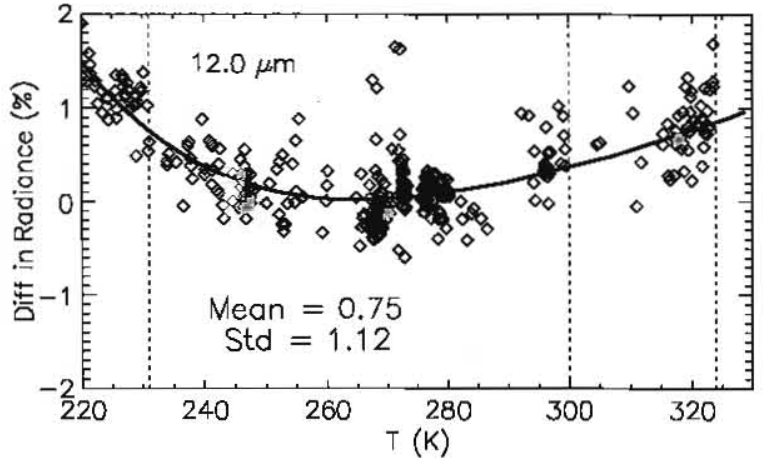

TABLE I

Relative Calibration DifFerences AND 1-Sigma STANDARD ERRORS BETWEEN MODIS AND AVHRR 11.0- AND 12.0- $\mu \mathrm{m}$ BANDS AT THE 0.3 TYPICAL, TYPICAL, AND 0.9 MAXIMUM RADIANCES IN TERMS of Temperature (In Kelvins) and Radiance (In Percentage)

\begin{tabular}{|c|l|l|l|l|}
\hline Band & $\mathbf{0 . 3 L t y p}(\mathbf{K})$ & $\mathbf{1 . 0}$ Ltyp (K) & $\mathbf{0 . 9 L m a x}(\mathbf{K})$ & Average (K) \\
\hline $11.0 \mu \mathrm{m}$ & $0.16 \pm 0.21$ & $-0.30 \pm 0.24$ & $-0.13 \pm 0.22$ & $0.09 \pm 0.42$ \\
\hline $12.0 \mu \mathrm{m}$ & $0.40 \pm 0.15$ & $0.36 \pm 0.21$ & $0.68 \pm 0.27$ & $0.32 \pm 0.42$ \\
\hline & $\mathbf{0 . 3 L t y p}(\%)$ & $\mathbf{1 . 0}$ Ltyp (\%) & $\mathbf{0 . 9 L m a x}(\%)$ & Average (\%) \\
\hline $11.0 \mu \mathrm{m}$ & $0.40 \pm 0.50$ & $-0.44 \pm 0.36$ & $-0.16 \pm 0.28$ & $0.39 \pm 1.16$ \\
\hline $12.0 \mu \mathrm{m}$ & $0.93 \pm 0.38$ & $0.50 \pm 0.28$ & $0.81 \pm 0.31$ & $0.75 \pm 1.12$ \\
\hline
\end{tabular}

shows the same differences shown in Fig. 5 in terms of radiance percentage, and results are also listed in Table I. Between $T$ 's at $0.3 L_{\mathrm{typ}}$ and $0.9 L_{\max }$, the differences are within $0.40 \%$ for the $11.0-\mu \mathrm{m}$ band, while for the $12.0-\mu \mathrm{m}$ band, the differences are $0.5 \%$ for $T$ at $L_{\text {typ }}$ and up to $0.8 \%-0.9 \%$ for either $T$ at $0.3 L_{\text {typ }}$ or $T$ at $0.9 L_{\text {max }}$. These differences are well within MODIS and AVHRR combined calibration requirements and indicate an excellent calibration consistency between the Aqua MODIS and NOAA-18 AVHRR bands at 11.0 and $12.0 \mu \mathrm{m}$. It is also noticed that the remaining differences are temperature dependent, particularly for the $12.0-\mu \mathrm{m}$ band. A cold-scene bias is observed for temperatures lower than $240 \mathrm{~K}$. At least half of the bias is due to MODIS calibration based on a comparison between MODIS and AIRS [18] and with in situ temperature measurements obtained in the Dome C area, Antarctica [19]. Improvements made in the upcoming MODIS Collection 6 L1B 
product will significantly remove most of the cold-scene biases. For temperatures larger than $300 \mathrm{~K}$, there might be land surface emissivity impacts if the emissivity has significant differences in spectral behaviors within the $11-12-\mu \mathrm{m}$ range. From a calibration point of view, how well the nonlinear behavior is characterized has a direct impact on the calibration for low or high temperatures because the temperatures of on-board $\mathrm{BB}$ are limited to a small range.

It should be pointed out that the differences found in this letter have minimum impacts on most skin temperature retrieval. This is because these retrieval algorithms are developed by regression against measurements such as buoy data [20], [21]. Thus, these algorithms are basically sensor dependent, and any constant calibration biases have been absorbed into the regression coefficients. We also analyzed the sensitivity of simulated $\Delta T$ to errors in column atmospheric water vapor content. A $15 \%$ change in water content only causes a $\Delta T$ change by less than $0.05 \mathrm{~K}$ at the typical temperature for a number of default atmospheric profiles provided by MODTRAN, indicating that impacts due to errors in retrieved water vapor product are generally negligible for cold to typical temperatures.

\section{CONCLUSION}

This letter has compared the calibration differences between the Aqua MODIS and NOAA-18 AVHRR bands at 11.0 and $12.0 \mu \mathrm{m}$ using SNO observations obtained in nearly parallel orbits. The temperature difference $(\Delta T)$ between the two sensors is used to evaluate their calibration at each scene temperature level from 0.3 of the typical radiance to 0.9 of the maximum radiance. The impact on $\Delta T$ due to the RSR differences between MODIS and AVHRR is estimated by MODTRAN simulations, and this effect is removed from observed $\Delta T$. The simulations use real-time atmospheric profiles of temperature, water vapor, atmospheric pressure and ozone, and surface skin temperatures obtained from the Aqua AIRS standard retrieval product. The results of this letter show that the remaining temperature difference is within $0.30 \mathrm{~K}$ (or $0.40 \%$ in radiance) across the entire temperature range for the $11.0-\mu \mathrm{m}$ band. For the $12.0-\mu \mathrm{m}$ band, the differences are $0.50 \%$ at the typical radiance and up to $0.90 \%$ at 0.9 of the maximum radiance. These results indicate an excellent calibration consistency between the Aqua MODIS and NOAA-18 AVHRR bands at 11.0 and $12.0 \mu \mathrm{m}$, respectively.

\section{ACKNOWLEDGMENT}

The authors would like to thank their colleague, Dr. G. Toller, for the helpful comments that he made on the original manuscript.

\section{REFERENCES}

[1] W. L. Barnes, T. S. Pagano, and V. V. Salomonson, "Prelaunch characteristics of the Moderate Resolution Imaging Spectroradiometer (MODIS) on EOS-AM1," IEEE Trans. Geosci. Remote Sens., vol. 36, no. 4, pp. 10881100, Jul. 1998.

[2] W. L. Barnes, X. Xiong, and V. V. Salomonson, "Status of Terra MODIS and Aqua MODIS," Adv. Space Res., vol. 32, no. 11, pp. 2099-2106, Dec. 2003.
[3] X. Xiong and W. L. Barnes, "An overview of MODIS radiometric calibration and characterization," Adv. Atmos. Sci., vol. 23, no. 1, pp. 69-79, Jan. 2006.

[4] A. P. Cracknell, The Advanced Very High Resolution Radiometer (AVHRR). Philadelphia, PA: Taylor \& Francis, 1997.

[5] G. Ohring, J. Tansock, W. Emery, J. Butler, L. Flynn, F. Weng, K. St. Germain, B. Wielicki, C. Cao, M. Goldberg, J. Xiong, G. Fraser, D. Kunkee, D. Winker, L. Miller, S. Ungar, D. Tobin, J. G. Anderson, D. Pollock, S. Shipley, A. Thurgood, G. Kopp, P. Ardanuy, and T. Stone, "Achieving satellite instrument calibration for climate change," Eos, Trans. Amer. Geophys. Union, vol. 88, no. 11, p. 136, 2007. doi:10.1029/2007EO110015.

[6] C. C. Walton, J. T. Sullivan, C. R. N. Rao, and M. P. Weinreb, "Corrections for detector nonlinearities and calibration inconsistencies of the infrared channels of the Advanced Very High Resolution Radiometer," J. Geophys. Res., vol. 103, no. C2, pp. 3323-3337, 1998.

[7] C. Cao, M. P. Weinreb, and J. T. Sullivan, "Solar contannination effects on the infrared channels of the Advanced Very High Resolution Radiometer (AVHRR)," J. Geophys. Res., vol. 106, no. D24, pp. 33 463-33469, 2001.

[8] C. Cao and A. Heidinger, "Inter-comparison of the longwave infrared channels of MODIS and AVHRR/NOAA-16 using simultaneous nadir observations at orbit intersections," in Proc. SPIE-Earth Observing Systems VII, 2002, vol. 4814, pp. 306-316.

[9] A. Wu, X. Xiong, C. Cao, X. Wu, and W. L. Barnes, "Inter-comparison of radiometric calibration of Terra and Aqua MODIS $11 \mu \mathrm{m}$ and $12 \mu \mathrm{m}$ bands," in Proc. SPIE-Earth Observing Systems IX, 2004, vol. 5542, pp. 248-258.

[10] X. Xiong, A. Wu, and C. Cao, "On-orbit calibration and intercomparison of Terra and Aqua MODIS surface temperature spectral bands," Int. J. Remote Sens., vol. 29 , no. 17/18, pp. 5347-5359, Sep. 2008.

[11] P. Ciren, C. Cao, and J. T. Sullivan, "Consistency in the long-term environmental measurements with NOAA Advanced Very High Resolution Radiometer," in Proc. SPIE-Remote Sensing and Modeling of Ecosystems for Sustainability III, 2006, vol. 6298, pp. 629810-1-629810-12.

[12] A. Berk, G. P. Anderson, P. K. Acharya, M. L. Hoke, J. H. Chetwynd, L. S. Bernstein, E. P. Shettle, M. W. Matthew, and S. M. Adler-Golden, MODTRAN4 Version 3 Revision 1 User's Manual. Hanscom AFB, MA: Air Force Res. Lab., Space Vehicles Directorate, Air Force Materiel Command, 2003.

[13] K. Kidwell, NOAA KLM User's Guide. Washington, DC: Dept. Commerce, NOAA/NESDIS, 2000.

[14] C. Cao, M. Weinreb, and H. Xu, "Predicting simultaneous nadir overpasses among polar-orbiting meteorological satellites for the intersatellite calibration of radiometers," J. Atmos. Ocean. Technol, vol. 21, no. 4 , pp. 537-542, Apr. 2004.

[15] E. F. Vermote, N. Z. El Saleous, and C. O. Justice, "Atmospheric correction of MODIS data in the visible to middle infrared: First results," Remote Sens. Environ., vol. 83, no. 1/2, pp. 97-111, Nov. 2002.

[16] J. Susskind, C. D. Barnet, and J. M. Blaisdell, "Retrieval of atmospheric and surface parameters from AIRS/AMSU/HSB data in the presence of clouds," IEEE Trans. Geosci. Remote Sens., vol. 41, no. 2, pp. 390-409, Feb. 2003.

[17] J. Qu, W. Gao, M. Kafatos, R. E. Murphy, and V. V. Salomonson, Eds., Earth Science Satellite Remote Sensing Data, Computational Processing, and Tools, vol. 2. Beijing, China: Tsinghua Univ. Press, 2006.

[18] C. J. Donlon, P. J. Minnett, C. Genternann, T. J. Nightingale, I. J. Barton, B. Ward, and M. J. Murray, "Toward improved validation of satellite sea surface skin temperature measurements for climate research," J. Clim., vol. 15, no. 4, pp. 353-369, Feb. 2002.

[19] B. N. Wenny and X. Xiong, "Using a cold earth surface target to characterize long-term stability of the MODIS thermal emissive bands," IEEE Geosci. Remote Sens. Lett., vol. 5, no. 2, pp. 162-165, Apr. 2008.

[20] D. C. Oesch, J.-M. Jaquet, A. Hauser, and S. Wunderle, "Lake surface water temperature retrieval using Advanced Very High Resolution Radiometer and Moderate Resolution Imaging Spectroradiometer data: Validation and feasibility study," J. Geophys. Res., vol. 110, p. C12014, 2005. doi: $10.1029 / 2004 \mathrm{JC} 002857$.

[21] Z. Wan, "New refinements and validation of the MODIS Land-Surface Temperature/Emissivity products," Remote Sens. Environ., vol. 112, no. 1, pp. $59-74$, Jan. 2008. 